\title{
LVIII. Method of ascertaining the value of growing timber trees, at different and distant periods of time
}

\author{
Mr. Charles Waistell
}

To cite this article: Mr. Charles Waistell (1809) LVIII. Method of ascertaining the value of growing timber trees, at different and distant periods of time, Philosophical Magazine Series 1 , 33:132, 327-332, DOI: $10.1080 / 14786440908562876$

To link to this article: http://dx.doi.org/10.1080/14786440908562876

曲 Published online: 18 May 2009.

Submit your article to this journal $\pi$

山 Article views: 2

View related articles 
Method to ascertain the Value of Growing Timber Trees. 327 which the sulphuric acid can have an action, act differently when there is an accession of atmospheric air. I have remarked in another Memoir, that it is not the coal which contains most pyrites, which gives in the inside of the mines the inflammable gas known by the name of firedamp, but rather the coal which contains little or none visible to the naked eye; and in which the sulphuret of iron probably exists in particles not discernible.

LVIII. Method of ascerlaining the Value of Growing Timber Trees, at different and distant Periods of Time. By $M x$. Charles Waisteli, of High Holborn*. SIR,

Concerving that the Tables contained in the annexed papers will afford useful information to growers of timber, and tend to encourage the growth of it in these kingdoms, and thereby promote the views of the Society of Arts, \&cc. I trust you will have the goodness to lay them before the Society, as I have formed them with great attention.

Having last autumn viewed some plantations made under my direction about thirty years ago, I found the value of one of them much to exceed my expectation. 1 became therefore desirous to devise some means of estimating what its value might probably be at different future periods. I was thus led to construct the first of these tables, and on the completion of this, other tables seemed necessary; and I was thus progressively led on to the construction of the whole. For this purpose I searched in various authors for the measure of trees, in girt and height, at different ages, and obtained similar information among my acquaintance. Hence I collected, that the increase in the circumference of trees is generally from about one to two inches annually, and from twelve to eighteen incbes the annual increase in height. Some fall a little short, and some exceed those measures.

- From Transactions of the Bociety for the Encouragement of Arts, Manufachures, and Commerce, for 1808. - The gold medal of the Society was voted to Mr. Waistell for this communication.

$\mathrm{X}_{4}$ 
I shall now briefly notice a few of the advantages to be derived from the first Table.

1st, The first Table shows every fourth year, from twelve years old to a hundred, the rates per cent. per annum at which all trees increase, whether they grow fast or slow, provided their rate of growth does not vary. This table may be the means of saving young thriving woods from being cut down, by showing how great a loss is sustained by felling timber prematurely *.

$2 \mathrm{~d}$, And it may be the means of bringing old trees to market, by showing the smallness of the interest they pay for the money they are worth, after they are 80 or 100 years old.

But this table shows the interest which they pay, only, whilst the trees continue growing at their usual rate. In case they fall short only a little of their usual increase in girl, this considerably diminishes the rate per cent. per annum of their increase. And trees do decrease in their rate of growth before they appear to do so $t$. A pale and mossy bark are certain indications of it.

3d, The first Table may also assist the valuer of such nimber as is not to be cut down, but to continue growing, by enabling him to estimate its present value more accurately

* "A wood, near West Ward, in Cumberland, of more than 200 acres, was felling in 1794, it was little more than 30 years old. The whole was cut away without leaving any to stand." See Miller's Gardener's Dictionary, last edition, under the Heal of Woods.

At 30 years old timber pays 10 per cent. for standing, and probably this wood might have paid 7 per cent. per annum on an average for the next $\$ 0$ years.

+ In Mr Pringle's Agricultural Report of Westmoreland is a paper of the Bishop of Landaff's, stating, "That a very fine oak, of 82 years growth, measured in circumference at six feet from the ground, on the 27 th of October 1792, 107 inches, and on the same day of the same month in 1793, it measured 108 inches." He then states the interest it paid to be only about 2 per cent., and says this tree was a singularly thriving one. It is evident that, with all this appearance of thriving, it was on the decline. For if we divide 108, its inches in circumference, by 82 , its age, we find its average annual increase had been one inch and a third. Its falling off to one inch reduced the rate per cent. of increase one-fourth.

than 
than is usually done, especially when it is increasing after a high rate per cent. per annum*.

The second Table shows the rate per cent. to be the same as in the first Table, though the annual increase is more both in height and circumference.

The third Table is calculated to show the number of trees that will stand on an acre of ground, at the distance of onefifth of their height, (which distance is recommended by Mr. Salmon, in a paper in the Society's 24th volume, and the number of feet the trees will contain, both those to be cut nut, and those to be left standing, at the end of every four years, from 16 to 64 years old, supposing they increase 12 inches in height and 1 in circumference annually. This distance may suit fir trees, but will be too near for oaks.

The fourth and fifth Tables show the same particulars when the trees grow at greater rates.

The sixth Table is calculated to show the same particulars when the trees are constantly thinned out every four years, so as to leave them at the distance of one-fourth of their height. According to this table there will be 48 trees left on an acre when they are 120 years old; and it seems generally agreed, that from 40 to 50 full-grown oak trees are as many as bave sufficient room to sand on an acre.

The seventh Table shows the same particulars respecting trees which increase 35 inches in height and $1 \frac{1}{2}$ inch in circumference annually,

The eighth Table shows the same particulars respecting trees which increase 18 inches in height, and two inches in circumference annually.

The ninth Table shows the same particulars as Table 6, till the trees are 28 feet high, after which the distance is increased from one-fourth to one-third of their height.

The 10th, 11th, and 12th Tables show the annual increase in boles of 24,32 , and 40 feet long, and the difference of their increase at the same ages.

* A fir wood of more than 30 acres, and about 30 years old, was lately valued to be sold with an estate, by several eminent wood-valuers, without taking into consideration its rate of increase. It was then increasing after the rate of 10 per cent. per annum, and probably would increase after the rate of 8 per cent. on an average for the next 20 years. 
To these Tables succeed comparative statements, showing the number of feet contained in boles of 'different lengths, when the trees are 60 years old ; by which it appears, that, if cut down at that age, the longest boles are not the most profitable to the growers of timber.

And $I$ have added the valuation of the plantations before alluded to, with remarks on them.

Having finished my introductory remarks, I conclude, and am, Sir, your very humble servant,

Charles Waistelc.

Talles respecting the Growth of Timber.

Calculations, showing every fourth year, from 12 to 100 , the progressive annual increase in the growth of trees, and gradual decrease in the rate per eent. per annum, that the annual increase bears to the whole tree.

The whple height of the trees is taken to the top of the leading shoot, and the girt in the middle; but no account is taken of the lateral branches.

If trees increase 12 inches in height and 1 in circumference annually, their increase will be as undermentioned, viz.

TABLE $\mathrm{I}$.

\begin{tabular}{|c|c|c|c|c|c|c|c|c|c|c|c|c|c|c|c|}
\hline \multirow[t]{2}{*}{ 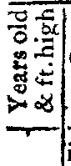 } & \multirow{2}{*}{ Girt. } & \multicolumn{3}{|c|}{ Contents. } & \multirow{2}{*}{ 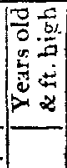 } & \multirow{2}{*}{ Girt. } & \multicolumn{4}{|c|}{ Contents. } & \multicolumn{4}{|c|}{$\begin{array}{l}\text { One year's } \\
\text { increase. }\end{array}$} & \multirow[t]{2}{*}{$\begin{array}{l}\text { Rate per } \\
\text { cent. of } \\
\text { increase. }\end{array}$} \\
\hline & & & in. & pts & & & & in. & pt. & sds. & & in. & pt. & sds. & \\
\hline 12 & $1 \frac{1}{2}$ & 0 & 2 & 3 & 13 & $1 \frac{5}{8}$ & 0 & 2 & 10 & 3 & 0 & 0 & 7 & 3 & $26 \cdot 8$ \\
\hline 16 & 2 & & D 5 & 4 & 17 & $2 \frac{1}{8}$ & & 6 & 4 & 9 & & 1 & 0 & 9 & 19.9 \\
\hline 30 & $2 \frac{1}{2}$ & & 010 & 5 & 21 & 25 & 1 & 0 & (3) & 8 & 0 & 1 & 7 & 8 & $15 \cdot 7$ \\
\hline 24 & $3^{+}$ & & 6 & o & 25 & $3 \vec{t}$ & 1 & 8 & 4 & 1 & 0 & 2 & 4 & 1 & 13. \\
\hline 28 & 3 & & 24 & 7 & 29 & 5 & 2 & 7 & 9 & 1 & 0 & 3 & 2 & 0 & $1 i^{\circ}$ \\
\hline 32 & 4 & & $\begin{array}{ll}3 & 6\end{array}$ & 8 & 33 & $4 \frac{1}{8}$ & - 3 & 10 & 9 & 6 & 0 & 4 & I & 6 & 9.67 \\
\hline 36 & $4 \frac{1}{2}$ & & 50 & 9 & 37 & $4 \frac{5}{8}$ & 5 & 5 & 11 & 5. & 0 & 5 & 2 & 5 & 8.5 \\
\hline 40 & 5 & & 611 & 4 & 41 & $5 \frac{1}{8}$ & 7 & 5 & 8 & 10 & 0 & 6 & 4 & 10 & $7 \cdot 6$ \\
\hline 44 & $5 \frac{1}{3}$ & 9 & 2 & 11 & 4.5 & $5 \frac{5}{8}$ & 9 & 10 & 7 & 9 & 0 & 7 & 8 & 9 & 696 \\
\hline 48 & 6 & 12 & 20 & 0 & 49 & $6 \frac{i}{8}$ & 12 & 9 & 2 & 3 & 0 & 9 & 2 & 9 & 6.38 \\
\hline 52 & $6 \frac{1}{2}$ & 15 & 53 & 0 & 53 & $6 \frac{5}{8}$ & 16 & $I$ & 10 & 2 & 0 & 10 & 10 & 2 & 5.9 \\
\hline 56 & 7 & 19 & 90 & 8 & 57 & $7 \frac{1}{8}$ & 20 & 1 & $\mathbf{1}$ & 7 & 1 & $\theta$ & 5 & 7 & 5.4 \\
\hline 60 & $7 \frac{1}{2}$ & 23 & 5 & 2 & 61 & $7 \frac{5}{8}$ & 24 & 7 & 6 & 6 & 1 & 2 & 4 & 6 & $5 \cdot 1$ \\
\hline 64 & 8 & 28 & 5 & 4 & 65 & $8 \frac{1}{8}$ & 29 & 9 & 7 & 0 & 1 & 4 & 3 & 0 & $4 \cdot 76$ \\
\hline 68 & $8 \frac{1}{2}$ & 34 & I & 4 & 69 & $8 \frac{5}{6}$ & 35 & 7 & 8 & 11 & 1 & 6 & 4 & 11 & 4.49 \\
\hline 72 & 9 & 40 & 6 & 0 & 73 & $9 \frac{1}{8}$ & 42 & 2 & 6 & 4 & 1 & 8 & 6 & 4 & 4.2 \\
\hline 76 & $9 \frac{\mathrm{x}}{2}$ & 47 & 7 & 6 & 77 & $9 \frac{5}{8}$ & 49 & 6 & 5 & 2 & $I$ & 10 & 11 & 2 & $3 \cdot 98$ \\
\hline 80 & 10 & 55 & 66 & 8 & 81 & $10 \frac{1}{8}$ & 57 & 7 & 11 & 9 & 2 & 1 & 3 & 9 & $3 \cdot 79$ \\
\hline 84 & $10 \frac{1}{2}$ & 64 & \pm 3 & 8 & 85 & $10_{\frac{5}{8}}^{\frac{5}{3}}$ & 66 & 7 & 7 & 8 & 2 & 3 & 11 & 8 & $3 \cdot 6$ \\
\hline 88 & 11 & 73 & 310 & 4 & 89 & $11 \frac{\pi}{8}$ & 76 & 5 & 11 & 1 & 2 & 7 & 7 & 1 & $3 \cdot 5$ \\
\hline 92 & $11 \frac{x}{2}$ & 84 & 5 & 9 & 93 & $11 \frac{5}{8}$ & 87 & 3 & 4 & 0 & 2 & 9 & 7 & 0 & $3 \cdot 3$ \\
\hline 96 & 12 & 96 & 0 & 0 & 97 & $12 \frac{1}{8}$ & 99 & 0 & 4 & 6 & 3 & 0 & 4 & 6 & $3 \cdot 15$ \\
\hline 100 & $12 \frac{1}{3}$ & 108 & 36 & 0 & 101 & 125 & 111 & 9 & 6 & 8 & 3 & 3 & 6 & 8 & 3. \\
\hline
\end{tabular}


In Table X. of the increase of a bole of 24 feet in height, of a tree growing at the above-mentioned rate, it will be observed, that the contents at 24 years of age are the same, and at 64 years nearly the same as in the above Table, but the contents of the bole at all the intermediate periods exceed the above. And a 40 feet bole exceeds the above contents from 44 years to 100, as may be seen in Table XII. For these reasons chiefly I did not think it necessary to take into consideration the decrease in height that takes place in trees at different ages, according to the kind of tree and quality of the soil.

The increase per cent. per annum is the same as the above in all trees at the same age, whether they have grown faster or slower, provided their increase in height and thickness annually has not varied on an average. The progress of trees is sometimes greatly retarded by insects destroying their leaves, by unfavourable seasons, and by their roots penetrating intu noxious strata. But these accidents cannot enter into calculations.

Calculations, showing every fourth year from 12 to 64 , the progressive annual increase in the growth of trees, and the grarlual decrease in the rate per cent. per annum that the annual increase bears to the whole tree.

The whole height of the trees is taken to the top of the leading shoot, and the girt in the middle; but no accolnt is taken of the lateral branches.

If trees increase eighteen inches in height, and two inches in circumference, annually, their increase will be as undermentioned, 'viz.

TABLE II.

\begin{tabular}{|c|c|c|c|c|c|c|c|c|c|c|c|c|c|}
\hline $\begin{array}{l}4 \\
0 \\
80 \\
80 \\
4 \\
4\end{array}$ & $\frac{50}{50}$ & 离 & Contents. & $\begin{array}{ll}\vec{c} & \dot{0} \\
0 & 0 \\
00 & 0 \\
4 & 5\end{array}$ & $\begin{array}{l}\vec{z} \\
\frac{\overrightarrow{D g}}{\vec{J}} \\
\vec{I}\end{array}$ & $\frac{ \pm}{5}$ & & onte & ents. & & $\begin{array}{l}\text { One year } \\
\text { increase. }\end{array}$ & & $\begin{array}{l}\text { Rate per } \\
\text { cent. of } \\
\text { increase. }\end{array}$ \\
\hline & feet. & in. & ft. in.pt. & & feet. & inch. & $\mathrm{ft}$. & in. & pt.s & & ft. in pt.s & & \\
\hline 12 & 18 & 3 & 116 & 13 & $19 \frac{1}{2}$ & $3 \frac{1}{4}$ & 1 & 5 & 1 & 0 & 37 & 0 & $26 \cdot 5$ \\
\hline 16 & 24 & 4 & 280 & 17 & $25 \frac{\bar{x}}{2}$ & $4 \frac{1}{4}$ & 3 & 2 & 4 & 0 & 064 & 0 & $19: 8$ \\
\hline 20 & 30 & 5 & 526 & 21 & $31 \frac{x}{2}$ & $5 \frac{x}{4}$ & 6 & $\dot{\mathbf{0}}$ & $\dot{3}$ & 6 & 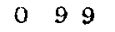 & 6 & 156 \\
\hline 24 & 36 & 6 & 900 & 25 & $37 \frac{1}{2}$ & $6 \frac{i}{5}$ & 10 & 2 & $\rho$ & 6 & 20 & 6 & 13. \\
\hline 28 & 42 & 7 & 1436 & 29 & $43 \frac{\pi}{2}$ & $7 \frac{1}{4}$ & 15 & 10 & 6 & 0 & 70 & 0 & Il: \\
\hline 32 & 48 & 8 & 2140 & 33 & $49 \frac{7}{2}$ & 8.5 & 23 & 4 & 8 & 0 & $\begin{array}{lll}2 & 0 & 8\end{array}$ & 0 & $9 \cdot 6$ \\
\hline 36 & 54 & 9 & 3046 & 37 & $55 \frac{I}{2}$ & $9 \frac{i}{4}$ & 32 & II & 7 & 6 & $\begin{array}{lll}2 & 7 & 1\end{array}$ & 6 & $8 \cdot 5$ \\
\hline 40 & 60 & 10 & 4180 & 41 & $61 \frac{\pi}{2}$ & $10 \frac{5}{4}$ & 44 & 10 & 3 & 6 & 25 & 6 & 76 \\
\hline 44 & 66 & 111 & 5556 & 45 & $67 \frac{\mathrm{r}}{2}$ & $11 \frac{1}{7}$ & 59 & 3 & 10 & 0 & 3104 & 0 & $6 \cdot 9$ \\
\hline 48 & 72 & 12 & 7200 & 49 & $73 \frac{1}{2}$ & $12 \frac{5}{4}$ & 76 & 7 & 1 & 0 & 71 & 0 & 63 \\
\hline 52 & 78 & 13 & 9166 & 53 & 792 & $13 \frac{1}{4}$ & 96 & 10 & 11 & 6 & 45 & 6 & $5 \cdot 8$ \\
\hline 56 & 84 & 14 & 11440 & $5 \pi$ & $85 \frac{\pi}{2}$ & $14 \frac{1}{4}$ & 120 & 6 & 8 & 6 & 28 & 6 & $5 \cdot 4$ \\
\hline 60 & 90 & 15 & 14076 & 61 & $91 \frac{1}{2}$ & $15 \frac{1}{4}$ & 147 & 9 & 2 & 0 & 18 & 0 & $5 \cdot$ \\
\hline 64 & 96 & $|16|$ & 17080 & 6.5 & 97 & $16 \frac{\pi}{7}$ & 1178 & 9 & 4 & 0 & ] 4 & 01 & $4 \cdot 7$ \\
\hline
\end{tabular}


Explanation of the Construction of Tables $\mathrm{I}$. and II.

To render the preceding tables easy to be understood by persons not accustomed to calculations, I will state the process of the operations in the first line of Table II.

The height of the tree at 12 years of age is supposed to be 18 feet to the top of its leading shool, aud 24 inches in circumference at the ground, consequently, at half the height, the circumference is 12 inches, - one-fourth of this, being three inches, is called the girt. The girt being squared and multiplied into the height, gives one foot one inch and six parts for its contents. At 13 years old the tree will be $19 \frac{1}{2}$ fet high, 26 inches in circumference at the ground, and 13 inches at half the height; one-fourth of 13 gives $3 \frac{1}{4}$ inches for the girt. This squared and multiplied into the height, gives one foot five inches and one part for the contents. Deduct from this the contents of the tree at 12 years of age, and there remains three inches and seven parts, which is the increase in the 13 th year. Then reduce the contents of the tree when 12 years old, and the increase in the 13 th year, each into parts, dividing the former by the latter, and the quotient will be $3 \cdot 76$; by this number divide 100 , and the quotient is 26.5 , which is the rate per cent. of increase made in the thirteenth year; consequently whatever the tree might be worth when 12 years old, it will, at the end of the 1 ath year, be improved in value after the rate of $26 l$. 10s. per cent., or in other words, that will be the interest it will have paid that year for the money the tree was worth the preceding year.

At every succeeding period, both in this Table and Table I., the like process is gone through.

[To be continued.]

LIX. Proceedings of Learned Societies. ROYAL SOCIETY.

A pric 13.-Earl of Morton in the chair. A paper by the Rev. Mr. Mc Gregor, on native arseniate of copper, was read. The existence of this substance in nature has long been held problematical, and its discovery in a mine between 